\title{
CIENTIFICAMENTE COMPROVADO (?): REFLEXÕES SOBRE O CONHECIMENTO CIENTÍFICO
}

\author{
I. Fortunato \\ Instituto Federal de Educação, Ciência e Tecnologia de São Paulo, Campus Itapetininga \\ ivanfrt@yahoo.com.br \\ Submetido 31/03/2016 - Aceito 07/03/2017 \\ DOI: $10.15628 /$ holos. 2017.4354
}

\section{RESUMO}

Neste artigo, a partir de importante coluna jornalística, buscou-se refletir sobre o significado subjacente ao termo "cientificamente comprovado", demonstrando que a construção deste tipo de conhecimento tende à argumentos aqui apresentados, contou-se com o apoio das ideias de Morin, Capra, Maturana e outros. Ao final, é esperado que esta comunicação colabore com as subjetividade e à visão parcial. Para embasar os discussões sobre a própria ciência.

PALAVRAS-CHAVE: ciência; verdades científicas; complexidade.

\section{SCIENTIFICALLY PROVEN (?): REFLECTIONS ON SCIENTIFIC KNOWLEDGE}

\section{ABSTRACT}

This article is based on important journalistic column and aims at reflecting upon the underlying meaning of the term "scientifically proven" by showing that the construction of such knowledge tends to subjectivity and partial view. To support the arguments presented, the article counts on the ideas of Morin, Capra, Maturana and others. Finally, it is expected that this work contributes to the discussions of science itself.

KEYWORDS: Science; scientific truth; complexity. 


\title{
CIENTIFICAMENTE COMPROVADO (?): REFLEXÕES SOBRE CONHECIMENTO CIENTÍFICO
}

\begin{abstract}
Depois de avaliar mais de 800 trabalhos publicados, um painel de 22 especialistas da larc (Agência Internacional de Pesquisas em Câncer) ouvidos pela OMS concluiu que o consumo de carnes processadas - salsicha, linguiça, bacon, salame, presunto, mortadela - está associado a um pequeno aumento no risco de câncer de cólon e reto [...] Não houve unanimidade sequer entre os 22 especialistas do painel da larc: sete deles se abstiveram de votar a favor das conclusões por não estarem convencidos da qualidade das evidências apresentadas ou por não concordarem com elas (Drauzio Varella, 2015, p. c10).
\end{abstract}

Este artigo começa com a reprodução de dois trechos da coluna do Dr. Drauzio Varella, publicada no Jornal Folha de São Paulo, no dia 31 de outubro de 2015. Mais do que um estilo próprio de redação, o uso da epígrafe, geralmente, tem o seguinte propósito: situar o leitorado no tema proposto, contextualizando-o através de alguma autoridade no assunto, buscando ratificar sua importância social, política, econômica etc.

Não obstante, o objetivo desta comunicação não é tratar sobre carnes processadas, embutidas e potencialmente responsáveis por algum aumento na probabilidade de seus consumidores desenvolverem certo tipo de câncer no sistema digestório. O tema aqui proposto foi tangenciado pelo médico possivelmente para fazer valer seu argumento final de que é possível minimizar os riscos individuais de câncer e outras enfermidades. Para isso, seria necessário ficar longe do fumo, incluir frutas e vegetais na alimentação diária, fazer exercícios físicos e consumir pouco álcool. Aí sim, torna-se possível usufruir, parcimoniosamente, do que ele denominou de "prazeres da carne", ou seja, os embutidos.

Assim, o que está subjacente ao longo da coluna apresentada pelo Dr. Varella é o conhecimento científico. Intencionalmente, ou ao acaso, o renomado médico faz menção a um aspecto científico que não faz parte da cultura popular, tampouco é recorrente nos anais da própria ciência, justamente porque jaz silencioso nas discussões a respeito de hipóteses, métodos, dados e resultados. Esse aspecto é a subjetividade da ciência, ou seja, a compreensão da construção do conhecimento científico que, apesar de sua pretensiosa neutralidade e objetividade, baseada em fatos, experimentos e dados concretos, é sempre pessoal. Ainda que isso possa ser rapidamente rejeitado - por conta dos fatos, experimentos e dados concretos - há de se considerar que toda ciência é produzida por alguém, em determinado lugar, em determinada época. Ademais, o conhecimento científico que é valorizado pela comunidade científica é aquele endossado por cientistas.

É justamente por conta dessa redundância (cientistas aprovam a ciência de outro cientista), que uma tese de doutorado só pode ser aprovada se for avalizada por um conjunto de pessoas altamente gabaritadas na mesma ciência que se apresenta a tese, e os periódicos de maior credibilidade são aqueles que utilizam o sistema conhecido como avaliação por "pares": dois ou três cientistas, de lauto conhecimento sobre determinada ciência, recebem o conhecimento produzido por um colega, na forma de artigo (paper). Esses, então, elaboram seu parecer sobre o trabalho desenvolvido pelo(s) cientista(s) que deseja(m) sua ciência publicada. $\mathrm{E}$ àqueles que não estão familiarizados com os procedimentos da academia, não é raro que o mesmo trabalho seja intensamente elogiado e recomendado pelo parecer emitido pelo cientista " $A$ ", ao mesmo tempo que, com a mesma intensidade, seja menoscabado e rejeitado pelo 
cientista "B". Ambos tiveram acesso aos mesmos fatos, experimentos e dados; o quê, senão a subjetividade da ciência, poderia esclarecer tal discrepância?

Tudo isso é evidenciado pelo Dr. Varella, ao relatar o "impasse" dos 22 especialistas diante da análise de mais de 800 pesquisas científicas, validadas por cientistas, tratando da mesma ciência. Segundo o que se apresenta na coluna, sete especialistas refutaram ou discordaram das evidências que já tinham sido avaliadas e validadas por outros cientistas. Então, no momento de considerar os embutidos como elementos potencialmente cancerígenos, abstiveram-se.

Em partes, tanto o impasse quanto a renúncia à decisão podem ser esclarecidas pelas ideias de que os elementos da vida não devem ser compreendidos como se vários "Fios de Ariadne ${ }^{1 "}$ estivessem ardilosamente emaranhados, sendo possível encontrar o começo e o fim de cada um, retirando-o da confusão, tornando-o uma verdade científica, clara, absoluta e, finalmente, compreendida. Essas ideias foram concebidas com a ajuda de Capra, que entende os mistérios da vida como uma teia, na qual os fenômenos se entrelaçam, ao invés de se "enroscar". Segundo Capra:

\begin{abstract}
Independentemente de quantas conexões levamos em conta na nossa descrição científica de um fenômeno, seremos sempre forçados a deixar outras de fora. Portanto, os cientistas nunca podem lidar com a verdade, no sentido de uma correspondência precisa entre a descrição e o fenômeno descrito. Na ciência, sempre lidamos com descrições limitadas... (Capra, 2006, p. 49-50).
\end{abstract}

Essas ponderações apresentadas até aqui ajudam a esclarecer a interrogação que foi expressa no título deste trabalho, pois o objetivo deste artigo é provocar reflexões sobre ciência, construção do conhecimento científico e o adágio "cientificamente comprovado", o qual indica ter revelado uma verdade absoluta sobre determinado assunto. Curiosamente, quem colabora com essas reflexões, às vezes, são autores refutados pela ciência neutra e objetiva.

Além do já mencionado Capra, Humberto Maturana, por exemplo, faz eloquentes constatações sobre o método científico, esclarecendo suas etapas, do fenômeno a ser explicado, passando pelas hipóteses explicativas e suas deduções (elaboradas a partir da experiência do cientista e da consulta às publicações de outros cientistas), até a realização das experiências que comprovam, ou não, as possíveis deduções. Contudo, Maturana (2001, p. 55-57) parece olhar atentamente ao desenvolvimento da ciência, pois afirma que esta: "é um domínio cognitivo válido para todos aqueles que aceitam o critério de validação das explicações científicas". Em outras palavras, a ciência edifica-se sobre a ciência, que se torna válida para e pelos cientistas.

Na mesma direção, Morin, Ciurana e Mota (2003), ao tratarem da teoria como elemento indispensável na construção do conhecimento, a qualificam como possibilidade para solução das questões apresentadas pela e para vida. Assim, a teoria não seria uma solução, mas um intermédio entre um sujeito pensante e o fenômeno que este se dispõe a esclarecer. Contudo, alertam os autores, o próprio sujeito pensante ou seus pares contemporâneos e/ou futuros, não podem dar-se por satisfeitos por terem encontrado uma "verdade". Pois, como vimos, essa verdade pode ser somente validada dentro de um número limitado de conexões. Daí, Morin, Ciurana e Mota (2003, p. 27) enunciam importante princípio para um pensamento complexo, ao

\footnotetext{
${ }^{1}$ Fio de Ariadne é uma metáfora. Segundo a mitologia grega, Teseu adentrou ao labirinto de Dédalo para enfrentar o Minotauro. Ariadne, filha do rei, teve a ideia de entregar-lhe um novelo de fio, sendo que ela estaria do lado de fora do labirinto. Após derrotar o inimigo, Teseu pode facilmente sair do enigmático labirinto, pois estava seguro pelo "Fio de Ariadne" (Adaptado de Pouzadoux, 2001, p. 82-83).
} 
constatar que "a descoberta de que a verdade não é inalterável [pois] é possível pôr em dúvida todas as verdades estabelecidas".

Há infindáveis conexões nos fenômenos e os cientistas acabam por selecionar algumas para a construção da própria ciência; isso permite avanços. Entretanto, esse avanço só acontece quando alguém - reiterando a subjetividade científica - não se convence de que a verdade posta é a única verdade possível. E diante sua própria inquietação, (re)inicia o trabalho de construção do conhecimento, conforme descrito por Maturana e já reproduzido neste artigo. E não é incomum um cientista colocar em xeque as verdades consideradas por ele mesmo ou por outros. O projeto "edge.org", por exemplo, que propõe uma questão anual a seus colaboradores (a maioria, senão todos, cientistas), perguntou, em 2008: "Sobre o que você mudou de ideia? Por quê?". Mais de 160 colaboradores deram seus depoimentos, ratificando a possibilidade de reconsiderar, a partir de outras conexões, um fenômeno que tinha sido tido como acabado.

Assim opera a ciência: edificando-se sobre si mesma, a partir de cientistas que propõem, validam, revisitam, repropõem, recuperam, contradizem... colocando-a dentro de seu motoperpétuo de constante busca de novos saberes, mesmo que sobre velhos assuntos. Há fenômenos que, em algum ponto, efetivamente esgotam-se, tornando-se teoremas; ainda sim, esses teoremas não são o fim da ciência, pois alicerçam a busca pela solução de novas e antigas investigações.

Um exemplo de inquietação antiga é a difícil comprovação ou impugnação de uma conjectura "nascida" no ano 1740, retratada na forma de ficção por Doxiadis (2001), na qual ele é sobrinho de um matemático que abandonou a carreira depois de anos tentando enfrentar a impossível tarefa de demonstrar a mais forte Conjectura de Goldbach. Com um enunciado simples, todo número par maior que dois é a soma de dois números primos. Tal conjectura tem desafiado a ciência matemática por mais de dois séculos e meio. Mesmo que Helfgott (2013) tenha vencido um dos enigmas propostos por Goldbach, ratificando a conjectura de que todo número impar, maior que cinco, é a soma de três números primos, o desafio que enlouqueceu Tio Petros ainda está à procura de um (possível) ponto final - se é que existe um.

Com isso, é possível considerar que as verdades científicas estão sempre sujeitas a reinterpretações, reformulações, contestações. Isso torna bastante relevante as "chautauquas" de Robert Pirsig que, ao se deparar com as infinidades de hipóteses e explicações científicas para os fenômenos, além das inúmeras questões existenciais postas pela filosofia, optou por colocar seu filho na garupa de uma moto e dirigir pelos Estados Unidos, provavelmente numa tentativa de mitigar suas próprias angústias a esse respeito. Por isso, em determinado momento, ele expõe:

Parecia que os períodos de duração das verdades científicas eram uma função inversa da intensidade da atividade científica. Assim, as verdades científicas do século XX pareciam ter um período de vida bem mais curto do que as do século passado, porque a atividade científica agora é bem maior. Se no próximo século a atividade científica duplicar, a expectativa de vida de qualquer verdade científica deverá cair para aproximadamente um décimo da atual (Pirsig, 1984, p. 111).

Em uma previsão bastante facunda, Pirsig, em 1974, parecia compreender o século porvir. Aparentemente, ele não estava imaginando, em 1974, o quanto as pesquisas científicas

\footnotetext{
${ }^{2}$ Link direto para a questão de 2008: http://goo.gl/S5PIF5, acesso nov. 2015.

${ }^{3}$ Segundo o próprio Robert Pirsig (1984, p. 13): “As chautauquas eram séries de palestras populares, muito em voga no século passado [séc. XIX] e em princípios deste século, que visavam edificar, divertir, aprimorar o raciocínio e fornecer cultura e informação ao espectador".
} 
circulariam pelo mundo em questão de cliques, dando aos cientistas acesso a mais conexões deixadas de lado nas primeiras investigações, permitindo que, cada vez mais, novas hipóteses sejam estabelecidas sobre o mesmo fenômeno que, rapidamente, ora parece ter sido solucionado por $X$, que logo é retificado por $Y$, que em pouco tem é requalificado por $Z$, até que um único fenômeno - descobrir se carne processada amplia as chances de câncer - é colocado em discussão para 22 especialistas que, após se debruçarem sobre 800 pesquisas, concluem que o consumo de embutidos "pode aumentar um pouquinho a chance de câncer"; mas, um terço deles se recusou a opinar por ainda sentir falta de evidências com as quais eles concordem.

Ao final de todas essas reflexões, há dois "recados" importantes para deixar registrado. 0 primeiro é direcionado à sociedade que está fora da produção científica, tendo acesso a ela por meio de (1) qualquer tipo de mídia, como a impressa, onde foi encontrada a coluna do Dr. Drauzio Varella (que também fala à população pela televisão), (2) nos locais de educação formal e não formal, e (3) pelos especialistas que se consulta em algum momento da vida: médico, dentista, nutricionista, engenheiro, arquiteto, advogado etc. O recado é: lembre-se deste artigo e de todas as contingências que envolvem a afirmação "isso é cientificamente comprovado, pode comprar, usar, comer, tomar etc.".

O segundo recado é para a comunidade acadêmica, colegas de profissão. Antes de tomar as ideias aqui apresentadas como um texto originado das ciências humanas e sociais, que admitem e encorajam os devaneios e permitem várias interpretações por meio de opiniões, ao menos permitam-se refletir um pouco sobre essa hipótese de que a ciência constrói-se sobre ela mesma e que, independente de qual área do conhecimento as pesquisas se desenvolvem, elas têm sempre um "toque" de subjetividade. Essa subjetividade está presente na escolha do tema a ser pesquisado, na seleção da metodologia, do referencial e da análise de dados. Aparece, ainda, na opção por reconsiderar estudos já apresentados que, assim como os sete especialistas mencionados pelo Dr. Varella, entenderam que as evidências identificadas até o momento não possuem qualidade suficiente para Ihes convencer.

Para encerrar essa (possível?) "chautauqua" é preciso expressar a importância da ciência, mesmo que, por conta de sua própria "natureza", nem sempre é capaz de oferecer à sociedade respostas prontas - não se sabe se comer embutidos é um ato catalisador de câncer, mesmo que algumas evidências indiquem que sim. A ciência é o constante desenvolvimento do conhecimento que, conforme preconizado por Pirsig, cada vez mais se apresentará de formas contraditórias: diferentes cientistas (pessoas) ao redor do mundo estão instigados pelo mesmo fenômeno, mas cada um só é capaz de dissecá-lo para compreendê-lo a partir de uma fundamentação teórica, filosófica e de método - e seus resultados nem sempre irão "convencer" seus pares, que irão tentar refutá-los, e vice-versa.

Ao final, eis um axioma: a cada fenômeno estudado à luz da ciência, centenas de estudos serão conduzidos e, esperar concordância entre eles, é mera ilusão de que a ciência é, tão somente, objetiva. 


\section{REFERÊNCIAS}

Capra, F. (2006). A teia da vida: uma nova compreensão cientifica dos sistemas vivos. Trad. Newton Roberval Eichemberg. 10a ed. São Paulo: Editora Cultrix.

Doxiadis, A. (2001). Tio Petros e a Conjectura de Goldbach. Trad. Cristiane Gomes de Riba. São Paulo: Editora 34.

Helfgott, H. A. (2013). Major arcs for Goldbach's problem. Disponível em http://arxiv.org/pdf/1305.2897v1.pdf, acesso nov. 2015.

Maturana, H. (2001). Cognição, ciência e vida cotidiana. Trad. Cristina Magro e Victor Paredes. Belo Horizonte: Ed. UFMG.

Morin, E.; Ciurana, E. \& Motta, R. (2003). Educar na era planetária: o pensamento complexo como método de aprendizagem no erro e na incerteza humana. Trad. Sandra Trabucco Valenzuela. São Paulo: Cortez.

PIRSIG, R. M. (1984). O Zen e a arte da manutenção de motocicletas: uma investigação sobre valores. Trad. Celina Cardim Cavalcanti. Rio de Janeiro: Paz e Terra.

Pouzadoux, C. (2001). Contos e lendas da mitologia grega. Trad. Eduardo Brandão. São Paulo: Companhia das Letras.

VARELLA, D. (2015, 31 de outubro). Os suplícios da carne. Folha de São Paulo, llustrada, c10. 